\title{
A IDÉIA DE PROGRESSO NO PROCESSO DE INSTITUCINALIZAÇÃO NACIONAL DAS CIÊNCIAS NO BRASIL: A SOCIEDADE AUXILIADORA DA INDÚSTRIA NACIONAL ${ }^{1}$
}

\author{
Heloisa María Bertol Domingues
}

Museo Nacional - Rua Joaquin Campos Porto, 278 - 278 Rio de Janeiro, 2j-Brasil-22460-190

\section{RESUMEN}

No Brasil, as primeiras instituções científicas que foram criadas ainda no tempo colonial, foram sociedades científicas, que professavam os valores daquele pensamento que identificava as luzes com as ciências.

Gostaria de destacar aqui o Auxiliadora da Indusria Nacional, criada logo após a independê, em 1825 e funcionando oficialmente desde 1827.

\section{ABSTRACT}

The first Scientific institutions in Brasil created during the colonial period, defended the value of the thought that identified Enlightenment with Science.

We would like to point out the roll played in the construction of the Nacional State by the Sociedade Auxiliadora da Industria Nacional, created after the independency, in 1825, although working officially since 1827 .

Penso que em todos os países onde as idéias do pensamento iluminista tiveram maior ou menor influencia, tanto as instituições como a política destes países justificaram-se em função das suas idéias e dos seus valores. O pensamento das Luzes que, como se sabe, fundou a noção de tempo histórico, recortando-o em épocas que indicavam a gradativa integração das diversas sociedades num caminho comum de desenvolvimento rumo a uma civilização indefinida, fez com que a política e as insti-

\footnotetext{
1 Este trabalho foi escrito para o IV Congresso Latinoamericano de História das Ciências c Tecnologia (Cáli, Colombia, jan./1995) sob financiamento da Fundaçao de Amparo a Pesquisa do Estado de São Paulo (FAPESP).
} 
tuições dos países nela se enquadrassem, pugnando pela noção de progresso material $^{2}$. Em tais conjunturas, as ciências, vistas como o veículo daquelas idéias, adquiriram um caráter pragmático e, paradoxalmente antiaristotélico, que se traduziu nas suas práticas institucionais.

No Brasil, as primeiras instituições científicas que foram criadas ainda no tempo colonial, foram sociedades científicas, que professavam os valores daquele pensamento que identificava as luzes com as ciências. As ciências que queriam instituir eram, no entanto, as ciências naturais, aquelas ciências que, através da exploração das riquezas que a terra podia oferecer, trouxessem o progresso ecônomico. Era o casamento das idéias que valorizavam o progresso com o pragmatismo preconizado anteriormente por Francis Bacon e que também havia moldado a estruturação das primeiras grandes sociedades científicas européias ${ }^{3}$. A primeira sociedade científica brasileira que se tem notícia, apareceu $\mathrm{em} 1772 \mathrm{com}$ o nome de Academia Científica do Rio de Janeiro e nela objetivavam desenvolver o estudo das ciências naturais, da física, da química, da agricultura, bem como da medicina cirúrgica e farmácia. Ela teve duração efêmera mas deixou alguns trabalhos que mais tarde foram publicados em Portugal ${ }^{4}$. Pouco mais tarde a Sociedade foi praticamente recriada com o nome de Sociedade Literária e, mostrava um objetivo bem definido que era desenvolver a agricultura, para promover a felicidade pública ${ }^{5}$. Esta sociedade, depois de oito anos funcionando, sofreu um violento fechamento pois os seus associados foram presos, acusados de divulgar a maldita filosofia das Luzes, fomentadora de sentimentos nacionalistas $^{6}$. Conforme declarações colhidas posteriormente ao fechamento daquela sociedade, as ciências foram ali prioritárias e eram relativas aos modos de facilitar os

2 A idéia de progresso era intrínseca ao conceito de civilizaçao, como bem mostrou Lucien Febvre (1962). Ela implicou numa filosofia da história, em que o esquema fundamental do pensamento guardava um segredo teológico de infinitude - que não morre- e,se traduzia num quadro cartográlico do progresso que apresenta a marcha da razao indo do Leste para o Oeste (Atenas, Itália, Paris, Londres, América), até a revoluçao americana e depois retornando a Paris, sob o chapéu de Napoleao, lembrou bem Dominique Lecourt (Du Progres dans l'Histoire. Revista Archimede \& Leonard, Paris, AITEC(1993-94), 9 a 12.

3 Os estatutos da Royal Society, criada $\mathrm{cm}$ 1663, denotam a influencia do pensamento baconianno, quando neles se afirma que o propósito e fim da Sociedade Real, é fomentar o conhecimento das coisas naturais e de todas as artes, manufaturas, práticas mecânicas, máquinas e inventos úteis por meio de experiências (...), examinar todos os sistemas, teorias, princípios, hipóteses, elementos, histórias e experiências de assuntos naturais, matemáticos, e mecânicos inventados... (STENGERS, I. L'Aflinité ambigüe: La Rêve Newtonian de la Chimie du XVIIIe. siècle. Org. SERrES, M. 1989: 297-319.

4 (DIAS), 1968: 105-71. Dentre os trabalhos publicados destacam-se a Memória sobre a Cochonilha ou o Tratado de História Natural, Química, Agricultura, Artes e Medicina, publicados em $1790 \mathrm{em}$ Lisboa.

5. Idem, p.114, nota 32 .

6 (SANTOS), 1993. 
trabalhos do agricultor e a saúde pública, pois, estudavam moléstias que podiam advir, por exemplo, do uso das águas, as quais analisavam ${ }^{7}$. Os políticos que a fecharam pareciam identificar ciências e subversão política, pois, estas poderiam implementar um projeto de infraestrutura social que viria dar bases a temida autonomia do país, uma vez que os seus estudos diziam respeito a agricultura, que era a primeira fonte de produção do país, e a saúde.

A autonomia política do país, cujo processo se iniciou com a vinda da família real para o Brasil em 1808, teve finalmente sua consolidação em $1822 \mathrm{e}$, o associativismo científico iniciado na colonia, ganhou novo impulso depois da independência reiterando os valores do progresso material. Várias sociedades científicas surgiram no Brasil no século XIX ${ }^{8}$, porém, eu gostaria de destacar aqui o papel que exerceu naquele contexto de construção do Estado nacional a Sociedade Auxiliadora da Indústria Nacional que, criada logo após a independência, em 1825 e funcionando oficialmente desde 1827, encerrava nos seus princípios fundadores valores pragmáticos dos conhecimentos que se mostravam veículos do progresso. Ela foi uma das instituições científicas que teve suas idéias orientadas pelo iluminismo que, pelo menos até meados do século XIX, dominaram o pensamento científico brasileiro ${ }^{9}$. Naquela sociedade, progresso era sinônimo de uma próspera economia da nação. No discurso inaugural da Sociedade, o orador dizia que

«Nenhum país floresce e se felicita sem indústria; por ser ela o móvel da riqueza, tanto pública como particular de uma Naçao culta e realmente independente...»1".

No Brasil, a sua riqueza tanto pública quanto particular consistia no que se podia extrair da terra. A agricultura de exportação era a base da sua economia e, neste sentido, cabia desenvolvê-la para realizar a propalada prosperidade da nação e, a Sociedade Auxiliadora da Indústria Nacional jogou, durante a maior parte da sua existência, todo o seu empenho científico para atingir tal fim.

\footnotetext{
7 Jacinto José DA Silva Quintão, O Patriota, n. 4, out.1813, apud DiAs, op. cit, p. 115.

8 Dentre elas destacaram-se, além da Sociedade Auxiliadora da Indústria Nacional, o Instituto Histórico e Geográfico Brasileiro (1838), a Sociedade Vellosiana especializada em ciências naturais (1850) e a Associação Brasileira de Aclimação (1873). A SAIN, além de mais antiga foi, ao lado do IHGB que funciona até hoje, a mais duradoura, funcionando desde 1827 até 1894 quando foi fundida ao Centro Industrial do Rio de Janeiro.

) DANTES, M. A. (1991), 378.

16 Almeida, I. A. P. de, Discurso que no faustíssimo dia 19 de outubro de 1827 , cm que foi instalada a Sociedade Auxiliadora da Indústria Nacional, recitou, Apud CARONE; 1978.
} 


\section{A Agricultura como meta das CiênCias Naturais na Sociedade AuXi- LIADORA DA INDUSTRIA NACIONAL}

A elite política e cultural do país acreditou e apostou numa espécie de destino agrícola do país e, acabou por fazer com que o Brasil se inserisse na cconomia mundial como um produtor de bens primários, ou seja, um exportador de riquezas naturais. Neste processo o papel das instituições científicas, como o Museu Nacional voltado para a história natural, ou o Jardim Botânico, ambos criados no tempo colonial, não foi negligenciável, muito pelo contrário. Porém estas, eram instituições oficiais, mantidas e estruturadas pelo govemo. As sociedades cientílicas, como a Sociedade Auxiliadora da Indústria Nacional, que apareceu na conjuntura pósindependencia, era iniciativa de particulares embora tivesse angariado logo a proteção do Estado. Julidicamente, teve a tutela do Ministério dos Negócios do Império, passando para a alçada do Ministério da Agricultura, Comércio e Obras Públicas em 1860, quando este último foi criado mas, manteve sua autonomia estrutural e as suas diretorias eram eleitas e mantidas financeiramente pelos seus sócios. Excepcionalmente podiam receber algum financiamento do Estado para o desenvolvimento de algum projeto proposto.

Embora a Sociedade fosse autônoma para eleger suas diretorias e independente para decidir que tipos de trabalhos desenvolveria ou com quais instituições manteria correspondência e trocaria objetos naturais, ela era uma auxiliar do governo, funcionando como uma espécie de órgão de consultoria sobre a concessão de licenças para desenvolver novas espécies agrícolas ou para instalar manufaturas de produtos novos no mercado, ou até mesmo para licenciar a fabricação de máquinas, a instalação de fábricas ou, por vezes, a exploração de minérios. Tal característica era um traço comum com as associações científicas congêneres tanto européias como americanas ${ }^{11}$, e se refletiam nos seus estatutos que denotavam o propósito de atender demandas políticas. O seu primeiro estatuto oficializado em 1831, dizia que o seu objetivo primeiro era:

"promover por todos os meios ao seu alcance, o melhoramento e prosperidade da indústria no Império do Brasil.»12.

O tipo de indústria cra principalmente a agrícola como especificavam os estatutos de 1848 no seu primeiro artigo onde dizia:

1 CAPEL, H. (1991), 409.

12 Estatutos da Sociedade Auxiliadora da Indústria Nacional. Rio, Typ. Imperial Scignot-Plancher, 1831, Art. $1^{\circ}$, p. 3 . 
【IDF́I \ DE PROGRESSO NO PROCESSO DE INSTITUCINALIZAÇÃO NACIONAL DAS CIÊNCIAS

\begin{abstract}
"A Sociedade Auxiliadora do Rio de Janeiro tem porfim promover por todos os meios ao seu alcance para o aperfeiçoamento da agricultura das artes, dos ofcios, do comércio e da navegação do Brasil; e auxiliar a nosssa nascente indústria com prêmios, certificados, publicações e exposições, segundo o uso das naçōes mais adiantadas na civilizaç่ão.»'3.
\end{abstract}

O apoio do Estado veio logo após a sua criação, quando o Imperador aceitou as justificativas de um especialista, o diretor do Museu Nacional, para a sua instalação. $\mathrm{Na}$ ocasião o diretor do Museu dizia que a criação da Sociedade se justificava porque em territórios tão extensos, de população diminuta e comunicações difíceis, era preciso aplaudir as iniciativas que visassem suprir as suas deficiências. Para ele, a superação das necessidades viriam com a mecanica e com as combinações do genio que eram um auxílio precioso para a exploração dos recursos que a natureza fornecia, bem como facilitariam a utilização das forças da água, do ar, ou do calor que eram, dizia, motores fáceis de se porem em atividade ${ }^{14}$. Para ele, a Sociedade era vista como um meio de difundir os conhecimentos que viriam colocar o país na marcha do espírito humano ${ }^{15}$.

Com tais objetivos a Sociedade Auxiliadora falou ininterruptamente sobre agricultura. A sua revista, que circulou desde 1833, jamais deixou de publicar sobre este assunto, o que fez da agricultura matéria presente em todos os seus números ${ }^{16}$. Esta era entendida na Sociedade como a arte de cultivar a terra, de modo que produzisse maior quantidade de vegetais, e de melhor condição do que os que produz espontaneamente, pois, (...) se não houvesse abundância de produtos, nem a indústria poderia elaborá-los, nem o comércio traficar com eles, nem as nações poderiam dar um passo na civilização, frisavam num de seus artigos ${ }^{17}$. O caminho para fazer multiplicar a produtividade da terra seria o dos conhecimentos científicos e, as ciências que diretamente influiam na produção agrícola eram, diziam, a botânica e a química e, além destas podiam também ter influências a meteorologia, a mecânica, a zoologia, ou a fisiologia vegetal ${ }^{18}$.

Tão forte era o valor atribuído as ciências que, no discurso de aniversário do ano de 1839 , o orador dizia que a Sociedade podia ser considerada

\footnotetext{
13 Estatutos da Sociedade Auxiliadora da Indústria Nacional. Rio, Typ. Brasiliensi de F. M. FERREIRA (1848), p. 5.

It Apud NeTO, L., Investigações Históricas e Científicas do Museu Nacional, Rio, Museu Nacional, 1870 , p. 40

15 Idem.

16 CARONE, op. cit., p. 24.

17 Revista $O$ Auxiliador; 6 (1839), p. 34.

18 Idem, p. 35. 
"uma indústria nacional das Ciências, que como um corpo científico, fará a nossa regeneração intelectual. Esta reunião de pessoas tão distintas, e que abrangem nos seus variados conhecimentos tudo quanto é objeto de arte, e ciência, prova (...) que a nossa sociedade será um dia o foco das luzes do Brasil; e que este espirito nacional, se vai estendendo pela nossa abençoada pátrial'.»

Agricultura e ciências formavam um binomio que na Sociedade Auxiliadora era entendido como o cimento da nação [agrícola]. Até mesmo nas relações que estabelecia com sociedades congêneres esta preocupação estava presente pois naquele ano de 1839 diziam no relatório anual que as corporações da Europa e da América com as quais vinham mantendo correspondencia todas tinham a mesma preocupação com os destinos dos respectivos países e destacavam dentre aquelas correspondentes, algumas instituições tradicionais, como a Academia Real de Ciências de Nápoles, com quem trocavam tanto sócios como plantas e sementes, o Real Instituto Bourbônico também de Nápoles, a Sociedade Propagadora de Conhecimentos Úteis da cidade de Lisboa, e a Sociedade Farmacêutica da mesma cidade, a Sociedade de Agricultura de Mulhouse na Alsácia e a Sociedade Politécnica Prática de Paris, com as quais trocava publicações ${ }^{20}$. Pouco tempo depois da publicação daquele relatório, reproduziam um artigo do conhecido frei José Mariano da Conceição Velloso que, escrito no final do século XVIII, mostrava-se muito atual, pois nele o autor alirmava que

"O melhoramento de qualquer ramo de agricultura e de indústria (...) quando aprofunda O seu conhecimento, acha ser sinônimo da melhoria de um Estado, da sua riqueza e da comodidade dos seus habitantes. ${ }^{21}$.

Aquele binômio aparecia também na estruturação interna da Sociedade Auxiliadora. Esta era dividida inicialmente em seis comissões que compreendiam além da comissão de Agricultura, a de Análises e Processos Químicos, a de Economia Doméstica e Rural que, entre outros, apreciava a qualidade dos solos, a de Artes, a de Fábricas e Comércio, além das comissões de Redação e Revisão de Memórias c a de Fundos ${ }^{22}$. Esta estruturação sofreu alterações ao longo do século, entretanto, algumas daquelas comissões se mantiveram e outras foram criadas. Em 1869 a Sociedade Auxiliadora contava com 10 comissões: a de Agricultura que se manteve, a de Indístria Fabril, de Máquinas e Aparelhos, de Artes Liberais e Mecânicas, de Comércio e

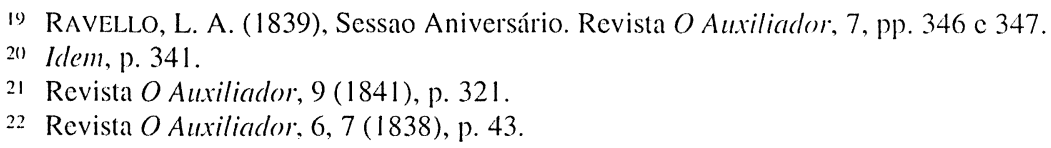




\section{A IDÉIA DE PROGRESSO NO PROCESSO DE INSTITUCINALIZAÇÃO NACIONAL DAS CIÊNCIAS}

Meios de Transporte, de Química Industrial e Geologia Aplicada, de Zoologia, de Estatística e Estatística Industrial, além das de Redação e de Finanças ${ }^{23}$. Além da comissão de Agricultura, haviam se mantido aquelas referentes ao fabrico de máquinas e desenvolvimento de inventos e tinham sido introduzidas as comissões de Estatística, de Zoologia e a Geologia que foi se somar a de Química. Todas denotavam o aspecto prático, voltado para a agricultura, que as ciências possuiam na instituição.

Embora a agricultura tivesse sido uma constante, os campos das ciências naturais que a ela se ligavam foram ganhando pesos diferentes ao longo do século XIX e foram introduzindo novos campos de estudo daquelas ciências. O fato se observa nos trabalhos anuais das diversas comissões da Sociedade, cujas alterações mostram também que estes possuiam uma relação direta com demandas sociais. O relatório anual referente ao ano de 1866 mostrou que de 9 requerimentos que o governo enviou para receberem os respectivos pareceres, 4 foram enviados para a seção de Agricultura, 2 foram para a seção de Química Industrial e Geologia Aplicada, o mesmo número foi para a seção de Indústria Fabril e 1 loi para a seção de Máquinas. Pouco tempo mais tarde observa-se uma inversão naquelas proporções, assim como os números de pedidos haviam dobrado. Dos 28 pedidos enviados a Sociedade, 11 foram encaminhados para a Comissão de Química Industrial c Gcologia Aplicada, 10 foram para a Comissão de Máquinas e apenas 3 para a de Agricultura, os demais eram dirigidos as seções de Artes Liberais e Transportes ${ }^{24}$.

A agricultura perdia parte do seu espaço na Sociedade, porém, em 1860 havia sido criado, por iniciativa da sua própria diretoria, o Imperial Instituto Fluminense de Agricultura e, esta nova associação passou a atuar como uma espécic de seção especializada em agricultura da Sociedade Auxiliadora. Assim, não fíca dilïil perceber porque a agricultura perdera seu espaço naquela instituição.

Numa primeira abordagem analítica aos trabalhos realizados por suas comissocs especializadas observa-se que a agricultura também fazia parte do universo de estudos de outras comissões, como por exemplo, da comissão de química c geologia. Era esta comissão que decidia sobre a viabilidade de aproveitamento, ou processamento industrial de determinados produtos provenientes da produção agrícola. Decidiam sobre a qualidade dos produtos apresentados, tais como os tintoriais, ou os tecidos obtidos das fibras de certas plantas, ou vinagre branco e aguardente obtidos da cana,

\footnotetext{
2.3 Estatutos da Sociedade Auxiliadora da Indústria Nacional. Rio, Typ. Dezesscis de Julho de J.A. dos Santos Cardoso, 1869, p. 14.

24 LEÃO, J. A. F. (1896), Relatório do Ministério de Agricultura, Comércio e Obras Públicas. Rio, Typ. do Diário do Rio de Janeiro, Ancxo F, 1896, p. 18.
} 
etc ${ }^{25}$. Na sessão de Máquinas, de um modo geral, as máquinas apresentadas tinham a finalidade de facilitar o trabalho na lavoura, visando substituir a mão-de-obra escrava. A seção de Agricultura propriamente dita, fazia o trabalho de intermediaria entre os produtos que entravam e saiam do país, distribuindo plantas e sementes aos produtores. Ela fazia a recepção e distribuição daquelas plantas visando enviá-las as províncias cujas condições naturais de clima ou solo eram mais próprias para a sua aclimatação. Esta atividade ela fazia $\mathrm{cm}$ comum acordo com o Jardim Botânico que também passou a ser adminstrado pelo Instituto Fluminense de Agricultura a partir de 1860.

Mesmo que a seção de Agricultura da Sociedade Auxiliadora se estivesse esvaziando, o fato não significava um esvaziamento concomitante da prioridade econômica do país. Apenas as dominâncias científicas em relação a agricultura é que alteravam-se.

\section{AS CiênCIaS PRIVILEgiadas Na SOCIEDADE AuXILIadora Da Industria NA- CIONAL}

As ciências naturais quando trabalhavam para o progresso agricola do país viram, naquela sociedade (e não somente nela) seu eixo de estudos se transportando da planta para o solo. Isto é, inicialmente, na medida em que interessava a introdução de produtos exóticos no país que fossem, no futuro, viáveis de se transformarem $\mathrm{cm}$ produção exportável, a botânica foi o ramo das ciências naturais que teve maior atenção. Nao somente para receber os produtos vindos dos países com quem o Brasil mantinha relaçoes diplomáticas, mas para, em contrapartida, promover as trocas de produtos nativos com aqueles países, as práticas botânicas de classificação de espécies e aclimatação foram de grande valia. A Sociedade Auxiliadora chegou a alugar um sítio para um dos seus sócios, um especialista naquela ciência, o alemão Ludwig Riedel.

Riedel tinha vindo para o Brasil, em 1823, com uma comissão naturalista chefiada pelo consul russo Langsdorf, e permaneceu no país inicialmente a serviço do governo russo, mas depois desligou-se deste para, em 1842, tornar-se oficialmente o chefe da seção de Agricultura e Botânica do Muscu Nacional26. Aliás foi auxiliado pelo diretor daquela instituição, Custódio Alves Serrao, que a Sociedade Auxiliado-

25 PARANHOS, J. M. da S.(presidente da SAIN) (1866), Relatório anual da Sociedade Auxiliadora da Indústria Nacional. Anexo ao Relatório do Ministério da Agricultura, Comércio e Obras Públicas, Rio, Typ. Nacional.

26 AUGEL, M. (1979). 
ra, em 1839, acedeu unanimemente ao aluguel do sítio que teria as funções de um jardim botânico ${ }^{27}$. Nele Riedel realizaria

"experiências sobre a cultura de certas plantas, e conhecimentos dos usos, e aplicação dos seus instrumentos agrários, introduzia (...) plantas exóticas e indígenas, quer medicinais, quer puramente úteis; e finalmente subministraria aos sócios aqueles esclarecimentos que quisessem ter acerca da cultura dos vegetais que se achassem no referido lugar ${ }^{28}$.

Na ocasião do aniversário da mesma, o secretário saudava o eminente consócio, Riedel, pelo seu esforço a glória que trazia nao somente a Sociedade mas, pelo que fazia para o

"adiantamento e melhoramento da agricultura brasileira.»").

Visavam a diversificação dos produtos cultivados e reconheciam que a iniciativa de Riedel significava a animação da agricultura do país pela ciência, reiterando o papel de agricultor do Brasil no contexto das nações.

Entretanto, na Sociedade Auxiliadora, a botânica não foi a única ciência considerada um meio para desenvolver a agricultura do país, ao seu lado, a revista da Sociedade divulgou constantemente artigos demonstrando o papel da química na agricultura. É preciso lembrar que a Sociedade Auxiliadora sempre manteve uma seção de Química. Esta no entanto foi mundando a sua abordagem. Inicialmente a comissão chamava-se Comissão de Análises e Processos Químicos e suas atividades prendiamse a química inorgânica em que a classificação e a enumeração dos elementos que continham plantas ou solos a caracterizavam. Algumas publicações adiantavam questoes da viabilidade dos solos para determinados cultivos, visando analisar a relação da sua composição com a maior ou menor umidade que apresentavam, como o fizeram num artigo publicado em 1839, denominado Meios de Apreciar a Qualidade dos Solos, onde, na parte referente a análise química dos solos diziam que

"as substancias que acabamos de assinalar como sendo mais ordinário encontram-se na composição das terras próprias para a cultura dos vegetais, retém água com mais ou menos força; elas existem em proporções mui diversas nos diferentes terrenos, no estado de areia siliciosa, de argila e de terra calcárea; e é para deterninar a quantidade de cada

27 Ata da Sessão Aniversário. Revista O Auxiliador, 7 (1839), 347.

28 Idem.

29) Idem. 
uma delas, e descobrir o seu modo de união que se submentem essas terras as experiências da análise.»30.

O mesmo tipo de análise faziam com os vegetais a fim de determinar, por exemplo, a qualidade das fibras daqueles que se apresentassem próprios para fabricação de tecidos ou de papel. As análises nestes casos buscavam determinar a resistencia das fibras ou a sua capacidade de unir as fibras com a sua mucilagem, determinando suas aplicações industriais ${ }^{31}$.

Aos poucos os trabalhos de química foram apresentando outros enfoques e, mais uma vez, as mudanças nos estatutos da Sociedade Auxiliadora os refletiram. Em 1857, quando a política do país sofria mudanças com o fim do tráfico de escravos decretado há pouco tempo (1850), na SAIN ocorreram mudanças na diretoria que trouxeram também refolmas. A Comissao de Química na reforma estatutária que sobreveio, passou a denominar-se Comissão de Química Industrial e Geologia Aplicada $^{32}$. Foi também esta nova diretoria, cujo presidente era um político eminente e descendente de família proprietária de terras na Bahia, Miguel Calmon du Pin e Almeida, o Marques de Abrantes, que promoveu a cnação do Imperial Instituto Fluminense de Agricultura que, como se disse acima, canalizou para este atribuições que até então caracterizavam a sua comissão de Agricultura. Ao mesmo tempo, na revista, passaram a divulgar, com bastante sistemática, artigos que mostravam alterações nas relações vigentes entre a agricultura e as ciências.

Os artigos publicados naqueles anos mostraram que plantas e solo já não cram analisados separadamente e os trabalhos publicados indicavam a importância de se conhecer a relação íntima de ambos. Assim, a reestruturação da comissão de química, além de dar novas atribuições aquela comissão, expressava a importância que ganhava o solo, pois, além de aliar química e geologia, a introdução da gcologia pode ser tomada como indicativo de uma maior preocupação com o solo e com o que dele poderiam tirar com maior lucro c não estavam preocupados somente com os minerais. Ao falar das relações solo/planta apresentavam uma imagem de ciclo de vida e faziam dois outros ramos das ciências naturais despontar como dominantes daquelas relações: a química orgânica ou química agrícola e a fisiologia vegetal.

A química agrícola estava diretamente relacionada a questão da qualidade do solo e o seu aparecimento nas páginas da revista da Sociedade Auxiliadora coincidia com um momento em que as lavouras tradicionais do país -a cana-de-açúcar e o cafésituadas $\mathrm{cm}$ terras litoraneas, vinham sofrendo enormes prejuízos em função de pragas que as dizimavam. As primeiras conclusões dos estudos que se realizaram então

31) Revista O Auxiliador; 7, (1839) p. 3.

3 Revista $O$ Auxiliador, 8 (1841), p. 226.

32 WERNECKDASILVA, J. L. (1979), pp. 103 a 105. 
apontavam o esgotamento do solo como o causador dos problemas com as plantações e, na revista eram publicados diversos artigos discutindo o assunto. Num destes artigos, o autor, fazendo apologia da obra do especialista austríaco Justus Liebig, dizia que os trabalhos deste último abriam os olhos para certos ensinamentos da própria ciência e da história, chamando atenção para a ignorância que haviam vivido nossos predecessores e que nós senamos muito mais ignorantes do que eles se

"reconhecendo a natureza exata dos substâncias que tiramos da tera, recusarmos restituir-lhes os elementos que a natureza não nos deu, mas que somente nos emprestou enquanto eles atravessam a torrente de nossa vida orgânica.».3.

Na mesma ocasião a revista da Sociedade publicava um outro artigo que criticava os métodos de fertilização do solo utilizado pelos ingleses, pois estes vinham utilizando ossos humanos que buscavam $\mathrm{cm}$ campos de batalha de toda a Europa, para adubar a terra. $\mathrm{O}$ artigo lembrava as críticas de Licbig aquela prática que acabava por tirar o cálcio da terra e inviabilizá-la para o cultivo e, aconselhava, como Licbig, o uso de excrementos humanos que estavam apenas poluindo os rios. E numa profecia apocalíptica concluia:

"O fim do mundo se aproxima! Não acabaremos por um terremoto, nem por um dilúvio); morreremos de fome (...) e isto por culpa dos senhores ingleses. (...) Há em agricultura unn princípio absolutamente verdadeiro: restituir à terra o que ela nos dá. A planta tira da terra os elementos que a constituem, depois de ter operado sobre eles certas transformações; os animais que se nutrem de plantas e os homens que se nutrem de plantas e animais transforman de novo os elementos que a terra forneceu; porém estes elementos não se perdem, e devem voltar, depois de haverem alimentado a vida, ao mesmo ponto donde partir(mm. $)^{34}$.

Os artigos sobre o assunto se multiplicavam pois na Sociedade Auxiliadora [da agricultura] haviam reconhecido que

"o crescimento das plantas não dependia somente da terra, do esterco, da água, da luz., do calor, e do armas de tudo isto a um tempo (...) então os agrônomos, se apoiando na

33 Revista $O$ Auxiliador, 31 (1863), p. 472. O artigo intitulava-se A nova obra de Licbig - As Leis Naturais da Agricultura, e era uma tradução de tradução francesa publicada cm Bruxclas. Licbig é considerado por muitos autores um dos iniciadores da química agrícola.

${ }^{34}$ Idem, p. 220. 
química e na fisiologia vegetal, procuraram investigar quais as substâncias que cada uma destas matérias forneciam aos vegetais.»\$.5.

Para eles, enquanto a química analisava as terras e reconhecia as suas propriedades, o estudo da fisiologia tinha o mesmo papel que a veterinária a respeito da animalidade, ela estudava as causas das doenças das plantas e os meios de removêlas ${ }^{36}$. Em última instancia, a fisiologia vegetal estava diretamente relacionada a vida das plantas, vida que só era possível quando planta e solo mantinham relações compatíveis, o que cabia aos estudiosos determinar. Naquela época $\mathrm{em}$ que aqueles artigos sobre a influencia da qualidade do solo nas plantas eram constantemente reproduzidos, a agricultura brasileira sofria graves prejuízos e, a Sociedade Auxiliadora, mostrando-se preocupada com os interesses dos grandes produtores agricolas do país divulgava as ciências que vinham em seu socorro. Estes ramos das ciências naturais dominavam naquele momento, o que não significa que eram os únicos tratados na instituição.

\section{CONCLUSÃO}

A grande valorização que ganharam as ciências naturais naquela associação científica deveu-se $\mathrm{em}$ grande parte ao caráter pragmático que haviam adquirido os conhecimentos. Esta valorização se refletia na organização estrutural da Sociedade Auxiliadora da Indústria Nacional. O seu modelo estrutural, embora não fosse original, pois seguia as congeneres européias que a antecederam e que, como ela, aliavam teoria e prática dos conhecimentos cientílicos, não pode ser tomado por um simples mimetismo. $\mathrm{O}$ modelo seguido na instituição guardava uma originalidade própria, pois, foi se transformando na medida em que as demandas sócio-políticas o cxigiam. Eram a estas demandas que a aplicação dos conhecimentos $\mathrm{e}$ as suas práticas científicas procuravam responder. Em última instancia, a associação pretendia, através da aplicação de conhecimentos científicos na base econômica do país, atingir um indefinido progresso.

As suas publicações mostram que, muito mais do que uma instituição que se propunha porta-voz do Estado, a Sociedade Auxiliadora instigou mudanças no sentido de propor e introduzir conhecimentos novos para aplicar principalmente a agricultura. Criada na conjuntura pós-independência en que economia buscava a sua inserção no mercado internacional através da maior exportação de produtos da terra, a botâni-

35 Revista $O$ Auxiliador (1865), 33, pp. 16-21.

31 Idem, p. 19. 
ca foi dominante na sociedade. Na segundo metade do século quando os produtos de exportação sofriam poblemas de produtividade devido ao aparecimento de pragas, novamente a Sociedade Auxiliadora difundia os conhecimentos científicos que podiam resolvê-los e, tratou de dar ênfase a química agrícola e a fisiologia vegetal, jogando por terra o mito do solo tropical indefinidamente fértil. Optou pela divulgação de conhecimentos que mais diretamente respondiam aos problemas que enfrentavam a economia do país e, neste sentido deu enfase a campos das ciências naturais que naquele momento eram importantes para realizar o que entendiam como o progresso do país. 


\section{HELOISA MARÍA BERTOL DOMINGUES}

\section{BIBLIOGRAFÍA}

Augel, M. (1979), Ludwig Riedel, um Viajante Alemão no Brasil. Salvador, Fundação Cultural do Estado da Bahia.

Capel, H. (1991), El Asociacionismo Cientifico en Iberoamerica. La Necesidad de un Enfoque Globalizador. International Congress - Science and Discovery of the New World - Madrid.

Carone, E. (1978), O Centro Industrial do Rio de Janeiro e a sua Importante Participação na Economia Nacional (1827-1977), Rio, CIRJ/Cátedra.

Dantes, M. A. M. (1991), Universalismo e Ciência no Brasil no Final do Seculo XIX. Internacional Congress - Science and Discovery of the New World - Madrid.

DiAs, M. O.da S. (1968), «Aspectos da Ilustração no Brasil». Revista do Instituto Histórico e Geográfico Brasileiro, 278 (1968), pp. 105-71.

Fevre, L. (1962), Pour une Histoire a Part Entiere. Paris, Ecole Pratique des Hautes Etudes.

LeCourt, D. (1993-94), «Du Progrès dans l'Histoire». Paris, Les Cahiers de L'Association Internationale de Techniciens, Experts et Chercheurs, n. 10.

—Relatórios do Ministério da Agricultura, Comércio e Obras Públicas (1860-1889)

-Revista O Auxiliador (1833-1884).

Santos, A. C. M. dos (1993), Ideologia e Poder no Rascunho da Nação. Rio, Secretaria Municipal de Cultura, Coleção Biblioteca Carioca.

Serres, M. (1989), Elements d'Histoire des Sciences. Paris, Bordas.

Werneck Da SiLva, J. L. (1979), Isto é o que me parece. Monografia de Mestrado, Niterói, Universidade Federal Fluminense. 